\title{
REFLEXIONES \\ HISTORICO FISICO NATURALES MEDICO QUIRURGICAS
}

Prácticos y especulativos entretenimientos acerca de la vida,

usos, costumbres, alimentos, bestidos, color,

$y$ enfermedades a que

propenden los negros de Africa, venidos a las Américas.

\section{Breve análisis}

de los reinos mineral, vegetal y animal.

\section{Finalmente}

se detallan en un discurso compendioso los conocimientos más útiles de la naturaleza.

Reuniendo en él los característicos sentimientos de la caridad española, para la conversión de negros, e yndios y el horror que estos tienen o conciven de las otras naciones europeas con particularidad a la anglicana, y República Francesa, de cuyas dos naciones han aprehendido estos infelices el esplin, es decir,

la última maldad de acabar la vida por sus mesmas manos.

\section{Livro Segundo y Período Segundo,}

Comenta esta obra, con varias adiciones y enfermedades nuevas, para vien de la humanidad.

\section{el Licenciado Francisco Barrera y Domingo}

\section{Havana}

23 de Julio de el año 1798. 


\author{
ADVERTENCIA PARA ENTRAR \\ AL SEGUNDO PERIODO, ESTO ES, \\ DE LAS ENFERMEDADES QUE EN LA TRAS- \\ MIGRACION DE LAS COSTAS DE AFRICA A LAS \\ AMERICAS, PADECEN LOS NEGROS EN \\ LOS BARCOS DE TRANSPORTE, ASI \\ YNGLESES, COMO OLANDESES, \\ FRANCESES, 8 .
}

Vien sé, amados Letores, que para tratar de esta materia que voy á explicar, se necesitaba de unos yngenios, tan sublimes, como los de una Academia Matritense, ó Valentiniana. Pero aunque serrano, pobre y sin balimiento humano, me he aplicado á acomodar mis observaciones o Ynquisiciones Historico Naturales Medico, Chirurgicas, de las enfermedades que padecen los miserables negros, en ambas Americas, por hallarme sumergido entre ellos, y contemplarlos al uso de la Patria, y principalmente de la sociedad humana.

Este espectáculo de la esclavitud, de tan pobrecitos negros, me inspiró una caridad, de suerte, que con ella, pretendo quitar los escrúpulos, á todos los que se persuadan, que todas mis empresas, trabajos, sudores, y curaciones, en estos, havandonados de todo el mundo, particularmente de yngleses y francese, carecen de utilidad a el vien de la humanidad censurandome satiricamente con aquella aclamacion de Persio:
O. curas hominum!
$\mathrm{O}$ quamtum est in rebus mane!

Sean muestra de mis tareas caritatibas, las presentes obserbaciones, de las principales enfermedades que padecen los negros de Africa, luego que los embarcan los estrangeros, para venderlos en las Américas, principalmente a todas las colonias españolas. Por esso, ilustres sabios, me sujeto a vuestra critica, suplicando dirijas un discurso aldeano, extrabiado, y me perdoneis si yerro. Porque conozco, que es muy fácil apartarme de el recto camino 
de la verdad, y como no soy mas que un cortisimo cirujano y tener que hablar de casos medicos.

Se conturba mi espiritu racional, quando veo tan lleno el camino médico de espinas, abrojos y dificultades. Y como é henprendido, una senda que se ha handado pocas veces, aun de los sabios yngleses, olandeses, franceses, $\mathcal{E}$., sobre las enfermedades que atacan a los pobres negros, sus esclabos, siendo éstos uno de los mas lucrosos ramos de su opulento comercio. Y porque no cuidan más de ellos en sus nabegaciones que si fuera una manada de carneros $y$ aun mucho peor.

Por cuya causa han crecido tanto en mi discurso, los dos que siempre he tenido a mis antagonistas que se ha llenado mi corazón de abrojos, cambrones, y espesas zarzas; tanto, que quasi me parece inpenetrable el salir vien. Pero con la ayuda de nuestro obnipotente y gran Dios, comfio abrir esta senda, y entonces habré echo una cosa agradable y caritatiba a la humanidad, tanto para consuelo de estos desgraciados racionales, como para sus amos, sean de la nación que sean éstos, E., pues por el bien de los pobrecitos negros esclabos nada omito y tamvién por utilidad, a los amos de yngenio, y curiosa a los médicos, cirujanos, acendados y a quantos tengan negros bajo la dura serbidumbre de una esclavitud. Dividire esta obra a las claves siguientes.

1 ro.

A las emfermedades mas comunes que por falta de la livertad, acometen a los negros en la larga nabegación de Africa a la América.

20.

Las mas principales especies, nombres, diferencias, causas, señales, vaticinios de estas emfermedades, que consisten en un estado depravado de toda máquina corporea, o de una parte considerable de ésta, complicada con alguna afeccion de el alma o de el sensorio.

30.

El distinguir y describir lo que palmariamente he visto, por centenares de veces, no sólo, en los armazones, á donde se venden 
los negros, sino en muchisimas emfermerias, de estas especies diferentes de emfermedades, que en realidad de verdad, son de un mismo género, aunque diferentes en especie, y que se obserban con mas frecuencia en ambas Américas.

\author{
CAPITULO 1 ro. \\ DE LA PRIMERA EMFERMEDAD \\ QUE PADECEN LOS NEGROS, EN LA \\ NABEGACION LLAMADA NOSTAL- \\ GICA, VULGO EL AMOR \\ DE LA PATRIA.
}

Para tratar con acierto de esta emfermedad de los negros, es necesario ante todas cosas, saber primero los placeres que les ofrece la sabia naturaleza en su pays. 2o. la diferencia que hallan en su economía animal con la mutación de un país de delicias, a la extrechez de un barco mercante, en donde se hallan con el principio de nuebas costumbres advenedizas.

\title{
PLACERES QUE PROPORCIONA A LOS NEGROS, LA CONTEMPLACION DE SU PAIS, EN LAS OBRAS QUE LES PROPORCIONABA LA NATURALEZA.
}

Aunque los negros por sus limitados discursos, no saben distinguir las obras de la naturaleza, como hacen los filosofos. No obstante les ofrece esta con una bondad maternal, unos placeres en su pais, los mas gratos, menos dispendiosos, y los mas unibersales de todos los placeres. Este es el que ya nuestros primeros padres gozaban en el campo damaceno.

Y sola la codicia humana de los hombres, por la sangre de estos infelices, es la que les a hecho vuscar nuebos generos de comercio y a los Negros nuebas emfermedades. Los hombres, muchas, y aun muchísimas veces, ( $y$ aun los animales), desprecian los vienes que gozan diariamente, por más excelentes que 
sean; porque todo su pensamiento es multiplicar y variar sus diversiones.

Con todo, el placer de que hablo de los negros, es muy digno de preferirse a los demas placeres porque aquel causa emfado y fastidio. Y éste, dexa en el alma mil delicias quando contempla a la naturaleza. Y como los negros en sus tierras las gozan sin gasto, ni sugeción alguna, es evidente, mirándolo con reflexión, que asi el pobre como el rico, el esclabo como el señor, pueden y se proporcionan este placer y gusto. Pero eso mesmo es lo que disminuye su aprecio. Tenemos tal vanidad, entre nosotros mesmos por estólidos que seamos, que un abanico, un cascabel, un espejo, E.,lo dexamos, y desestimamos por él lo que los demás gozan con nosotros, quando si fuéramos razonables, todas aquellas frusilerias y vagatelas, nos havian de dar emfado. Y sólo haviamos de aspirar a buscar otro vien, que es el pensamiento de lo que hace la felicidad de nuestros semejantes, no menos que la nuestra. (Vien que diversa, por los colores.)

La comparacion a estos placeres de la naturaleza, a los demás placeres, es tan distinto, como que para aquél todas las cosas son frívolas y engañosas, pues las diversiones tan estudiadas y tan magníficas que buscan los poderosos, los medianos y aun los de infima pleve con tantos cuidados, gastos, estudio, trampas y ardides. Dexan en el alma cierta comoción, que por vuenas que sean causan disgusto y enfado.

En lugar de las que ofrece la verífica, savia y rica naturaleza continuamente, no sólo a los negros e yndios, sino también a los demas hombres, ésto es, nuebos placeres, recreos y objetos, que no sólo son capaces de desterrar las melancolias más profundas, sino de estirpar millares de emfermedades y precaber otras imfinitas causas que tal vez serían nuestra ruyna y perdición, como se ebidencea de las fatales resultas que de esta causa resultan a los negros. Esto es en algunas castas de ellos.

Todos los placeres de que los hombres gozan, no son otra cosa que ensayos de nuestra imaginación mal fundada; por eso duran tan poco, y son tan fugitibos como un hermoso sueño, cuyas ilusiones y encantos se desvanecen al dispertarse. Pero los pla- 
$\begin{array}{lllllll}R & E & V & \text { I } & S & T & A\end{array}$

LATINOAMERICANA

DE PSICOPATOLOGIA

F U N D A M E N T A L

ceres naturales, estimados aún de los animales mas domésticos, (y de los hombres) aun de los mas estolidísimos, por fundarse en la razón y el corazón, son aquellos que el hombre gusta, contemplando un ser infinitamente savio, aunque incógnito a las limitadas luces, de los yndios y negros, vien que sus obras, por un instinto racional de el alma, son sólidas y constantes, porque les dejan en su imaginación una fuente inagotable de nuebas delicias. V. G.

El sol, la luna, el cielo estrellado, la tierra esmaltada de flores, el canto melodioso de las aves, los varios paysages, cerros, montes, colinas, prados, selbas, ríos, fuentes, $\mathcal{E}$., sin otras muchas cosas más deliciosas a la vista, que les ofrecen continuamente nuebos motibos de satisfacción y de alegria.

Comfieso que me dirán, que los negros e yndios son insensibles a ellos, pero esta mesma prueba rechaza mi conclusión. Es verdad. iY acaso ellos tienen la culpa de mirar indiferentemente las obras de la naturaleza, como la tienen el demás resto de los hombres, que tienen otra moral y otra educación? La gran ciencia de los europeos devía de ser, el disfrutar inocentemente de quanto le rodea, y saberse aprobechar de todo, teniendo el arte de hacerse feliz y sociable, con estos miserables, en todas las circunstancias, con muy poca costa, sin que por esso padeciese la virtud de la caridad, vasa fundamental de el Christianismo. Mas dexemos la naturaleza y volbamos al Cap. 1ro.

\section{S primera.}

\section{DE LA NOSTALGIA DE LOS NEGROS.}

Muy pocos autores describen de este afecto, aunque Buchan en su Medicina Doméstica Tom. 3, Pag. 301 - 302 hace mención de esa emfermedad. Vien, que primero que Buchan ya lo trató Juan Jacobo Scheuchzero en los opúsculos de la Academia Bono niense, en la pág. 307. Esta es una emfermedad muy propia de los negros de la nación Vivi, Carabali, Minas, E., quando los sacan de su pais para transportarlos los yngleses, franceses, y 
olandeses, a las Américas, por lo menos, es mas familiar a estas naciones que a las otras esta casta de negros. Cuando no pueden arrojarse a la mar quando vienen embarcados, se ponen tristes, asta que mueren, si no se les complace con algun engaño, y si quando han llegado al paraje, conque los an engañado y ven que les han quebrantado la palabra, callan, y aguardan la suya, para ausentarse de sus compañeros, y entonces van y se hechan en los pozos, los ríos o en la mar; porque están en la creencia, que haciendo esto, quedan libres de los europeos y que buelben a sus tierras.

\section{DESCRIPCION DE ESTA EMFERMEDAD NOSTALGICA.}

No se puede entre los negros comprobar la verdadera y acertada distinción de esta tristeza y melancolia, porque no se ha podido indagar su diferencia, si procede de delirio melancólico o de la melancolía morbo. Pero mi genuino sentir es, que en los negros no se ha verificado jamás, que haya procedido de melancólico delirio, sino de una melancolia morbífica cuya definición es la siguiente:

\section{DEFINICION DE ESTA MELANCOLIA DE LOS NEGROS.}

En una tristeza melancólica que les acomete repentinamente, sin delirio, furor ni calentura, nacida de una tenaz abersión a quantas cosas puedan substraerlos de su imaginatiba, como no sea la vuelta a su amada patria.

\section{DE LAS CAUSAS MAS COMUNES DE ESTA EMFERMEDAD EN LOS NEGROS.}

La abriguación de las causas de que pende principalmente, este afecto, es la continua vibración de aquellas fibras medulares de el cerebro a que están pegados, aún los vestigios impresos de las 
ideas de la patria. Pero como se hallan otras causas mas remotas, o antecedentes internas y que éstas son varias, y ocultas dentro de el cuerpo de el negro que suscitando el... para repartir otras, no sólo patricias, sino amorosas, a algún objeto, o displicentes, por nuebas y advenizadas costumbres, con las quales o maltratados o destituidos de la asistencia necesaria, se entristecen continuamente, y de ay se toma también, el que ellos esten siempre meditando en la patria.

$\mathrm{O}$ en la adversión al sujeto que puede motibarles otras causas distintas, que las de la patria, concurren a éstas algunas causas externas, como la mutación de estaciones, climas, alimentos, $\mathcal{E}$. Es constante, que la mutación de ayres no contribuye poco para perbertir la disposición de la sangre y de los espíritus, como también el trato diario con los estrangeros.

$\mathrm{Y}$ a éstos, se les puede añadir los sentimientos de las injurias, a que no están acostumbrados, como son, incomodidades, pesadumbres, E. Todas estas causas juntas son el principal motibo para ellos, de adquirir esta emfermedad nostálgica, los negros de todas edades, pues el mudar de vivir, de el seno de su país, entre sus amigos y sus madres, por una esclavitud forzada, por aquellos Régulos, con quanta repugnancia, no dejarán sus costumbres, opuestas enteramente a las de los yngleses, franceses, olandeses, dinamarqueses, portugueses y españoles, $\mathcal{E}$.

Pero aunque todas estas causas que llevo mencionadas pueden concurrir a ser la causa de esta enmfermedad nostálgica, no obstante, imbestigaré la causa, en su primer origen, con metodo geográfico.

Habitan los negros en las costas, llanuras, montañas, serranias, y quebradas de toda el Africa, entre los diez grados de latitud septemtrional, asta los treinta y tres grados de la mesma latitud; entre estas alturas soplan los vientos nordeste y sudeste. Desde los 33 grados de latitud septentrional hasta los 84 , los vientos son muy varios y generalmente más violentos, ésto es, entre los trópicos, y es la causa, porque hallándose detenidos por las montañas, sierras $\bar{y}$ arboledas, aquel viento general que corre de oriente a occidente, retrocede hacia la parte opuesta, a la dirección que 
seguia; y como la Africa es tan montuosa y los negros en todas estas montañas gozan de un temple muy venigno, que les hace de una organización muy sana, así como también en todos estos territorios africanos, ésto es, en todo el Reyno de Congo, en Angola, se hallan muchísimos ríos caudalosos, como son el Quilla, el Zoyre y el Quanza, y llueve en aquellas tierras con mucha abundancia y como las copiosas llubias y continuadas, junto con los havundantes rocíos, los truenos, relámpagos y rayos, los vientos constantes y a veces furiosos, y la inmensidad de exalaciones aromáticas que estos negros respiran juntas con la anchurosa libertad de que gozan, son los preserbativos de que se vale la savia naturaleza para precaberlos en sus regiones africanas, de tan extraña emfermedad. Ahora:

Solo querran saber los savios médicos, hablo de los poco versados en la historia natural, de que modo la naturaleza executa estas operaciones, no sólo, para que las himitemos, sino también, para que nos libertemos de muchas y diversas emfermedades, que no se conocen sino en la sociabilidad y gentes opulentas.

Y así digo, que luego que la atmósfera se halla cargada de vapores, las vemos caerse por su propio peso en forma de llubia o rocío, y éste es el primer modo con que se limpia el ayre de la putrefacción que tenia. Las exhalaciones de las materias sulfúreas o podridas, son impelidas de los vientos contra las montañas y las arboledas, por ser entre los trópicos las noches tan largas como los dias; son frías y húmedas, y las montañas y arboledas, lo son mucho más, que la atmósfera, de tal manera, que en llegando cerca de ellas, las exhalaciones se condensan y transforman en nubes, que se deshacen en llubias, hay relámpagos, y truenos que paran en rayos, $y$ de este modo queda puro y sutil y espirituoso el ayre.

Aora digo, que si todo quanto llebo dicho, no satisface, satisfará el saver el peso con que el ayre comprime el cuerpo de un negro en el campo, al que le comprime en el barco a donde lo traen embarcado.

El peso o columna conque el ayre comprime nuestro cuerpo en el campo es de 39,900 libras inglesas quando el barómetro señala 30 pulgadas de altura. El de la mar es 36,500 quando el mesmo baró- 
$\begin{array}{lllllll}R & E & V & \text { I } & S & T & A\end{array}$

LATINOAMERICANA

DE PSICOPATOLOGIA

$F \cup N D A M E N T A L$

metro señala 24 pulgadas de altura y de aquí se sacará la diferencia que ay en el ayre, para que los negros faltándoles esta porción de ayre, contraigan la emfermedad mencionada.

\section{DE LAS SENAALES DIAGNOSTICOS DE ESTA EMFERMEDAD, SEGUN HANDE No TH. 9.}

Las señales que manifiestan los negros en esta emfermedad, son las siguientes: se ponen repentinamente tristes, se esconden entre las escotillas de el barco, no quieren comer ni menos baylar, a lo que son sumamente afectísimos, miran con indignación quanto hacen los blancos, sus enemigos capitales, mayormente si son yngleses o franceses. No pueden tolerar aun los juegos mas chanceros de ellos mesmos, huyen, vuscando los mayores escondrijos, y si los yngleses los fuerzan con la amenaza, se hacen mil pedazos o se harrojan si pueden a la mar, pero estas son las señales precursoras: Vamos a hora a las que indican estar ya incipiente esta enfermedad.

Son varios los señales que anuncian tener esta enfermedad ya los Negros, y son la primera una tristeza grande que se apodera de su entendimiento, (aunque poco) que de depende de un oculto rencor en no podersen vengar de el desprecio, que reciven de los blancos o injurias que les hacen estos. En 2o. lugar, es el no haverse podido haberiguar ya por sus cortas luces, o ya por no podersen explicar por su torpisima lengua, vien es verdad que por los negros que se hallan civilizados, se ha descuvierto, por entender su modo de havlar, el que tienen una pasión furiosa de querersen volver a su pais, por algún objeto amado, que halla dejaron, vgr. madre, padre, o hijo, $\mathcal{E}$.

En semejante caso, siempre quieren estar durmiendo aunque con un sueño, turbado, aneloso, y con extremecimientos convulsivos, los quales, quando se dispiertan, se levantan, andan como atontados, hacen como que no oyen, y si se les fuerza a que atiendan a lo que se les dice, se impacientan y ensoverbecen, y suelen por esta causa apoderarsen de ellos unas vigilias contumaces y continuas, las que los devilitan de fuerzas, porque se emperran en no 
querer comer, ni menos vever, aunque tengan hamvre y sed que los mate.

De aqui les vienen unas palpitaciones y extremecimientos de corazón, con temblores en las manos y lavios, que los vuelve pusilánimes y de un animo apocado y havitado, por lo que si algunos se curan de esta enfermedad, se vuelven lelos, y atontados, notándose claramente, ser todo su pensamiento, el volver a su patria, pues si se halla otro negro conocido, y de su propio país el que les havle su propia lengua, se halegran, y le preguntan por su patria, y si tiene deseos de volver a ella, y si no les dá algunas vuenas esperanzas, se les empeoran los sintomas, y si no muere luego, a lo menos, siempre se halla peor hasta que lo harrebata una muerte violenta.

\section{DE QUE MODO SE VALDRA EL FACULTIVO, PARA VATICINAR EN LOS NEGROS SOBRE ESTA ENFERMEDAD.}

Es sumamente inpertinente, cansado y molesto, el pronósticar de esta enfermedad en los negros, a causa de su rudeza, incapacidad y brutalidad, pues además de ser una enfermedad en ellos peligrosísima, y el médico, no poder, ni menos saver, el origen de su primera causa que aflige a el negro, para seguir por ella la indicación curativa, pues ni ellos saven explicarse, ni menos se halla paciencia en el médico, para sugetarse, aunque sea por señas, a indagar el origen de tal enfermedad, lo cierto es, que los facultativos curan y visitan a estos desgraciados, mucho peor que si fuera un jumento.

Siempre a reinado en mí, la caridad y el desinterés con esta porción de el genero humano, y mis semejantes; y así, he escudriñado las más ocultas causas, relativas a las preguntas siguientes, que han sido el polo fixo para manejarme en todas sus curaciones, ésto-es, con los negros bozalones recién venidos de la Africa, pues con los negros criollos, riollos y ladinos ay mucha diversidad, pues éstos, pecan por carta de más, y aquellos, por carta de menos, como solemos decir en vuen español. 
$\begin{array}{lllllll}R & E & V & \text { I } & S & T & A\end{array}$

LATINOAMERICANA

DE PSICOPATOLOGIA

F U N D A M E N T A L

\section{PREGUNTAS RELATIVAS A SAVER DE LOS NEGROS, LAS CAUSAS PREDISPONENTES DE SEMEJANTE ENFERMEDAD.}

La 1ra. pregunta será, a qué diversión eran más aficionados, si al vaile, música, E.., quando estavan sanos, en su país. 2o., si estavan enamorados. 3o. a qué géneros de alimentos eran mas acostumbrados, y que les agradaven más. 4o. a qué género de enfermedades eran mas conaturalizados, si al jaus, erisipelas, sangre de espaldas, fluxo hemorrohidal, culevrilla, gota coral o epilepsia, dolores y vértigos de caveza, E.,De estas preguntas, venía en conocimiento el rumbo que havia de tomar para el vaticinio y empreender con acierto la curación; ésto se hace por medio de otro negro intérprete.

Pero mucho más que lo que acavo de decir, y que les hacarrea a cuantas desgracias se hacen, y egecutan los negros por la nostalgia, es la grande antipatía que les causan los blancos, con preferencia los de pelo roxo, como vgr. yngleses, olandeses, E. Lo he confirmado ésto, con muchísimas observaciones y notavles experiencias hechas a el intento, y me han salido muy ciertas; y la mesma antipatía cogen a los negros criollos, si de ellos reciven alguna injuria y no pueden vengarse.

\section{EXEMPLO, PROBADO EN TODAS LAS OCASIONES.}

Se ha aprobado por diferentísimas veces, el exemplo de ser verdadero, seguro, y cierto, el pronóstico sovre la enfermedad que estoy refiriendo, valga la experiencia más que mil raciocinios. Atacado un negro de semejante enfermedad nostálgica por causa de algún ultrage hecho por algun blanco ruvio, y tamvién, para algún criollo negro, así en ovras como en palavras, que el negro, por este motivo se entristece, y pone melancólico, no hay otro remedio, si no quieren que infalivlemente muera, sino pronto acariciarlo y darle alguna satisfacción amorosa, con la qual, el negro untrajado, venga en conocimiento, que a el injuriante, le pesa haverlo así tratado. He aquí, curado luego el negro, y cierto un baticinio, para la enfermedad. 
De esta mesma manera, se podrá hacer el vaticinio de las demás causas ya mencionadas, contejando a un mesmo tiempo la fuerza de la causa, con la seguridad de el prenóstico. Vgr. savida cosa es, en la medicina, que una fuerte presión en el corazón, oriunda de una pasión de ánimo, por supresiones havituales y acostumbradas, o vien de otras enfermedades orgánicas, son mucho mas fáciles de curar, que aquellas, que nacen de continuados afectos de el alma o de disposiciones hereditarias, por notarse diariamente, que una hemorragia de narizes, una diarrea viliosa, una sarna, enpeines o herupciones cutáneas, regreso de las reglas, almorranas fluentes, $\mathcal{E}$. desvanecen frecuentemente, varias enfermedades estrañas, y así voy a el regimen y curación.

\section{DE LA CURACION Y REGIMEN QUE CONVIENE SEGUIR, CON LOS NEGROS ACOMETIDOS DE LA NOSTALGIA.}

Para tratar de la curación de los negros, acometidos de semejante enfermedad, es necesario ante todas cosas, considerar el ayre que los rodeava en el Africa en tierra; a el que les rodea, en el buque que los conduce a las Américas, en la grande travesía, mayormente, quando en esta vienen apiñados, como rebaño de carneros.

Quiero, para más clara inteligencia, primero, el manifestar que los ayres de aquellas costas africanas, según el parecer de el juicioso médico Boncio son tan sutiles, raros y puros, como que son calientes de día y frescos de noche: teniendo al mesmo tiempo una lebedad tan sutil, que se introduce tan suavemente en los poros cutáneos de los negros; y como siempre andan desnudos, todos los túvulos e intersticios, asi de el sistema arterial como de el linfático, se hallan livres de contraer la putrefacción, y a el no ser así, todos aquellos vivientes africanos se hallarian en un continuo entumecimiento, a el modo de como se hallaría un perro u otro animal si lo pusieran dentro de la máquina pneumática, que luego, por la presión de el ayre, rebentaria. 


\section{Francisco Barrera y Domingo (1763-1803)}

Nació en la aldea aragonesa de Arroyofrío, en 1763. Su entrenamiento como cirujano tuvo lugar en el hospital de Zaragosa, famoso por lo revolucionario de su Asilo de Dementes. Como empleado de la marina de guerra española estuvo destacado en Puerto Rico, Santo Domingo y Nueva Granada antes de su llegada a la Habana, en 1780. Liberado de sus responsabilidades militares, encontró empleo como cirujano de esclavos en las grandes plantaciones de azúcar del occidente cubano. El libro del cual hemos tomado estos fragmentos constituye el segundo volumen en una trilogía sobre las enfermedades de los habitantes de las Antillas. Barrera murió en La Habana en 1803. El resto de su obra se ha perdido.

Rev. Latinoam. Psicopat. Fund., São Paulo, v. 11, n. 4, p. 791-804, dezembro 2008 (Suplemento) 